\title{
AS REPRESENTACCÕES DO ENSINO DE CIÊNCIAS DE UM GRUPO DE PROFESSORES DO ENSINO FUNDAMENTAL: IMPLICAÇÕES NA FORMAC̣ÃO CIENTÍFICA PARA A CIDADANIA
}

\author{
DAYVISSON LUÍS VITTORAZZI ${ }^{*}$ \\ https://orcid.org/0000-0001-9907-5173 \\ ALCINA MARIA TESTA BRAZ DA SILVA ${ }^{* *}$ \\ https://orcid.org/0000-0001-5424-9993
}

RESUMO: Fundamentado no referencial teóricometodológico da Teoria das Representações Sociais, com atenção especial a sua abordagem estrutural, o presente trabalho trouxe como objetivo identificar o conteúdo e a organização das representações do ensino de ciências construídas por um grupo de professores do Ensino Fundamental de um município no Estado do Espírito Santo, tratando de suas possíveis relações com o processo de formação científica nessa etapa da Educação Básica. Por meio de técnicas aplicadas à Teoria do Núcleo Central, foi possível perceber que o ensino de ciências é representado, em maior teor, como o mecanismo de ensinar conceitos e procedimentos característicos das ciências. Os termos CONHECIMENTO, LEITURA e OBSERVAÇÃO são centrais nessa representação. A identificação dessas representações sociais possibilitou ponderações sobre como esses professores concebem o objeto em questão e como este orienta suas ações, convergindo em discussões sobre sua materialização no processo de formação científica para o exercício da cidadania.

Palavras-chave: Ensino de Ciências. Representações Sociais. Professores do Ensino Fundamental.

LAS REPRESENTACIONES DE LA ENSEÑANZA DE LAS CIENCIAS DE UN GRUPO DE MAESTROS DE LA EDUCACIÓN PRIMARIA: IMPLICACIÓN EN LA FORMACIÓN CIENTÍFICA PARA LA CIUDADANÍA

RESUMEN: Basado en la referencia teórico-metodológica de la Teoría de las Representaciones Sociales, con especial atención a su enfoque estructural, el presente trabajo tuvo como objetivo identificar el contenido y la organización de

*Mestre em Ciência, Tecnologia
e Educação. Docente da Educação
Básica no município de Castelo - ES.
Pesquisador do Laboratório de Pesquisa em
Educação em Ciências e Representações
Sociais do Programa de Pós-Graduação em
Ciência, Tecnologia e Educação - Centro
Federal de Educação Tecnológica Celso
Suckow da Fonseca (CEFET/RJ).
E-mail:< <llvittorazzi@gmail.com>.

** Doutora em Educação. Docente
e pesquisadora do Programa de Pós-
Graduação em Ciência,Tecnologia e
Educação - Centro Federal de Educação
Tecnológica Celso Suckow da Fonseca
(CEFET/RJ). Coordenadora do Laboratório
de Pesquisa em Educação em Ciências e
Representações Sociais do Programa de
Pós-Graduação em Ciência, Tecnologia e
Educaçãa - Centro Federal de Educação
Tecnológica Celso Suckow da
Fonseca (CEFET/RJ).
E-mail: < alcina.silva@cefet-ri.br >.

* Mestre em Ciência, Tecnologia e Educação. Docente da Educação Pesquisador do Laboratório de Pesquisa em Educação em Ciências e Representações Sociais do Programa de Pós-Graduação em Ciência, Tecnologia e Educação - Centro Suckow da Fonseca (CEFET/RJ).

** Doutora em Educação. Docente e pesquisadora do Programa de PósGraduação em Ciência, Tecnologia e Tecnológica Celso Suckow da Fonseca (CEFET/RJ). Coordenadora do Laboratório de Pesquisa em Educação em Ciências e Representações Sociais do Programa de Pós-Graduação em Ciência, Tecnologia e Educação - Centro Federal de Educação Fonseca (CEFET/RJ). E-mail:<alcina.silva@cefet-rj.br >.

\footnotetext{
' Centro Federal de Educação Tecnológica Celso Suckow da Fonseca Universidade CEFET/RJ, Rio de Janeiro, RJ - Brasil.
} 
las representaciones de la enseñanza de las ciencias construidas por un grupo de maestros de la Educación Primaria de un municipio en el estado de Espírito Santo, tratando sus posibles relaciones con el proceso de formación científica en esta etapa de la Educación Básica. Por medio de técnicas aplicadas a la Teoría del Núcleo Central, fue posible percibir que la enseñanza de las ciencias está representada, en mayor contenido, como el mecanismo de enseñanza de los conceptos y procedimientos característicos de las ciencias. Los términos CONOCIMIENTO, LECTURA y OBSERVACIÓN son fundamentales para esta representación. La identificación de estas representaciones sociales permitió reflexionar sobre cómo estos maestros conciben el objeto en cuestión y cómo éste guía sus acciones, convergiendo en discusiones sobre su materialización en el proceso de formación científica para el ejercicio de la ciudadanía.

Palabras clave: Enseñanza de las Ciencias. Representaciones Sociales. Maestros de la Educación Primaria.

\section{THE REPRESENTATIONS OF SCIENCE TEACHING AN ELEMENTARY SCHOOL TEACHERS GROUP: IMPLICATIONS FOR SCIENTIFIC TRAINING FOR CITIZENSHIP}

ABSTRACT: Based on the theoretical-methodological reference of the Theory of Social Representations, with special attention to its structural approach, this paper aimed to identify the content and the organization of the representations of the science teaching constructed by Elementary School teachers group of a city in the State of Espírito Santo, dealing with their possible relations with the process of scientific formation in this stage of Basic Education. By means of techniques applied to the Central Core Theory, it was possible to perceive that the teaching of sciences is represented, in greater content, as the mechanism of teaching concepts and procedures characteristic of sciences. The terms KNOWLEDGE, READING and OBSERVATION are central to this representation. The identification of these social representations made it possible to ponder how these teachers conceive the object in question and how it guides their actions, converging in discussions about their materialization in the process of scientific formation for the exercise of citizenship.

Keywords: Science Teaching. Social Representations. Elementary School teachers. 


\section{INTRODUÇÃO}

Como o ensino de ciências é reproduzido por professores de ciências naturais do Ensino Fundamental? Esta questão orientou o objetivo de identificar o provável conteúdo cognitivo-estrutural da representação social do ensino de ciências mantida por um grupo de professores do Espírito Santo, tratando de suas possíveis relações com o processo de formação científica nessa etapa da Educação Básica.

Trazemos como prerrogativa um olhar para o espaço educacional, guarnecido de relações sociais cotidianas, no qual são produzidas e difundidas instâncias como a identidade, o discurso, a representação e a ação, dentre outras (JOVCHELOVITCH, 2004). Nesse espaço figura, dentro do conjunto de conhecimentos produzidos pela humanidade, o ensino das ciências da natureza.

Sob esse influxo, pesquisas na área do Ensino de Ciências tendem a considerar as estruturas do conhecimento do aluno, do professor e da própria ciência, no interesse de assinalar possíveis caminhos para uma "formação científica que permita aos cidadãos participar na tomada de decisões, em assuntos que se relacionam com a ciência e a tecnologia" (CACHAPUZ et al., 2005, p. 25). Nesse contexto, intensificam-se processos que orientam a importância da "alfabetização científica" por meio de uma educação estruturada na ciência e na tecnologia. Mesmo diante da polissemia associada à expressão, é possível afirmar que suas pretensões convergem na reestruturação dos objetivos básicos para o ensino no empenho de uma formação científica multidimensional, conduzindo atenção para outras dimensões do conhecimento científico e tecnológico, suplantando os modelos conceituais e procedimentais intrínsecos a esse processo (CACHAPUZ et al., 2005).

Nesse universo, os estudos de Representações Sociais (doravante RS) têm trazido consideráveis contribuições ao campo educacional, uma vez que se dispõem a investigar a elaboração de saberes e condutas por via de interações insígnias que compõem as relações humanas cotidianas (CAMPOS, 2017; GILLY, 2002; MOSCOVICI, 2007, 2012).

Tais prescrições conduziram, no presente trabalho, a produção de um diagnóstico do tema em questão, o qual se aproxima dos inquéritos psicossociais, frequentemente desenvolvidos em pesquisas no campo da Psicologia Social. Segundo Jovchelovitch (2004), as produções deste campo de estudos têm se dedicado ao detalhamento da zona turva e complexa que envolve as relações entre o indivíduo e a sociedade, o que fornece relevantes contribuições para um diálogo interdisciplinar, substancial aos temas científicos.

\section{REFERENCIAL TEÓRICO-METODOLÓGICO}

\subsection{0 ensino de ciências e a formação científica para a cidadania}

A evolução social humana, impulsionada pelos processos de globalização e consolidação da democracia, tem exigido das pessoas uma maior interação com as mais diferentes questões que surgem nesse contexto. Podemos apontar o desenvolvimento científico e tecnológico como impulso para novas demandas no 
mercado de trabalho, bem como o fortalecimento democrático como exigente de novas posturas frente às questões advindas desse desenvolvimento.

Partindo dessas asserções, diferentes iniciativas mundiais surgiram com o intuito de discutir os impactos desse crescimento científico e tecnológico nas sociedades. Esses intentos originaram referências que tratavam de alertar os "países para o fato de que a pobreza no mundo não se configura apenas pela carência de recursos naturais ou de parques industriais ou de serviços, mas sobretudo pela exclusão da participação na geração e no uso do saber científico" (BIZZO, 2012, p. 153). Em sua análise, o autor complementa que "um cidadão que não compreenda o modo de produzir ciência na modernidade será certamente uma pessoa com sérios problemas de ajuste no mundo" (BIZZO, 2012, p.154).

Sinalizamos, nesse sentido, a implicação do ensino de ciências na promoção da cidadania, uma vez que, considerando fundamental a interação dos indivíduos com questões públicas que envolvem a ciência e a tecnologia, o que acautela direitos de participação na vida política, não é cabível desconsiderar a necessidade de expandir o nível de conhecimento científico e tecnológico da sociedade.

A reiterada presença do tema nos meios de comunicação de massa e os debates globais têm promovido o surgimento de trabalhos de investigação que tratam com elevada importância de uma educação estruturada nas interações entre a ciência, a tecnologia e a sociedade como meios à alfabetização científica (CACHAPUZ et al., 2005). Inferimos, no entanto, que há certas dissidências quanto ao uso do termo "alfabetização", impulsionadas pelos debates estabelecidos nos estudos da linguagem ao proporem a noção de "letramento" (CUNHA, 2017). Para o autor, estudos sobre "letramento científico" (scientific literacy) já aconteciam desde o final da década de 1950 nos Estados Unidos e já apresentavam um caráter controverso, visto que à definição do termo cabiam variações conforme o grupo de interesse e o público-alvo. Não trazemos como intenção, porém, discutir essas variações, mas sinalizar para a necessidade imprescindível de ultrapassar o uso básico do conceito de alfabetização, não a restringindo à ideia de "ler e escrever", mas ampliando suas relações para significações mais densas como cultura e erudição (LORENZETTI; DELIZOICOV, 2001).

O trato da ideia de alfabetização remete, ademais, à estruturação de objetivos básicos para o ensino e isso exige estratégias que ultrapassem os esquemas conceituais e procedimentais que tangem esse processo. $\mathrm{Na}$ perspectiva de construir um currículo científico básico, pesquisadores apontam para algumas dimensões comuns nas diversas propostas tratadas no campo do Ensino de Ciências. Krasilchik e Marandino (2007), ao citarem os empreendimentos da Biological Sciences Curriculum Study (1993), destacam quatro estágios na alfabetização científica: nominal, vinculado ao reconhecimento de termos específicos do vocabulário científico; funcional, atrelado à capacidade de definir estes termos, sem compreensão plena de seus significados; estrutural, associado à percepção de ideias básicas que fundamentam o atual conhecimento científico; e multidimensional, que abrange a compreensão integrada dos saberes instruídos, estabelecendo vínculos com outros arranjos disciplinares.

Outra interpretação nos é apresentada por Shen (1975), também tratada por Gil-Pérez e Vilches (2001) e Krasilchik e Marandino (2007), ao discorrer sobre 
três diferentes dimensões da alfabetização científica, considerando seus objetivos e suas relações com o seu conteúdo e o público-alvo. Para o autor, a alfabetização científica prática possibilita a utilização dos conhecimentos na vida diária com a finalidade de resolver problemas básicos; a alfabetização científica cívica permite às pessoas uma intervenção social, com critério científico, em decisões políticas; a alfabetização científica cultural está relacionada com os níveis da natureza da ciência, com o significado da ciência e da tecnologia e a sua incidência na configuração social, em geral atribuída a uma pequena parcela da população.

É possível sinalizar, no entanto, que programas de ensino de ciências em que há a prevalência de esquemas de retenção conceitual ainda se difundem no cenário hodierno. Tais programas tendem a minimizar discussões sobre os diálogos entre a ciência, a tecnologia e as questões sociais, promovendo a difusão de ideias ingênuas ${ }^{1}$ ou distorcidas sobre o trabalho científico. O que se pretende, todavia, na perspectiva da alfabetização científica para a cidadania, é uma formação que permita ao aprendiz "compreender que o conhecimento científico é cumulativo e historicamente arquitetado, tendo sempre um caráter tentativo" e, por isso, abrange falhas, estando incurso "nas relações sociais, políticas, econômicas e ideológicas em que é produzido” (KRASILCHIK; MARANDINO, 2007, p. 24).

Parece-nos profícuo, nesse contexto da educação em ciências, apesar de não terem sido produzidos neste campo, tratarmos dos aportes dos estudos da sociologia da ciência desenvolvidos por Bruno Latour. ${ }^{2}$ Em obras como: Jamais fomos modernos: ensaios de antropologia simétrica (1994), A vida de laboratório: a produção dos fatos cientificos (1997) e Ciência em ação: como seguir cientistas e engenheiros sociedade afora (2000), o autor discute acerca dos mecanismos "sociotécnicos" de produção dos fatos científicos. Para o autor, o que cientistas manipulam em seus laboratórios podem ser denominados de "híbridos", ou seja, as considerações produzidas pelos cientistas são produtos de observações, com o auxílio de equipamentos, intermediadas por contextos científicos e políticos, configurando-se, assim, uma rede de atores humanos e não-humanos atuando mutuamente na produção de conhecimentos. Assim, toda produção científica é social, mas também é resultado de implicações do discurso e, igualmente, decorrências de fenômenos naturais, mas não pode ser moderada apenas por esses fatores (LATOUR; WOOLGAR, 1997). Logo, um produto científico é sempre "um híbrido construído pela rede de cientistas, teorias, equipamentos e técnicas que o cercam" (LIMA; OSTERMANN; CAVALCANTI, 2018, p. 373).

A esse contexto, Latour (1994) acrescenta a ideia de que não há uma separação objetiva entre natureza e sociedade. A existência de um fato científico está associada à rede que o produziu e, por essa interação, natureza e sociedade são constituídas conjuntamente. "Sociedade [...] também é construída, tanto quanto a natureza" (LATOUR, 1994, p.95). Para o autor, a ideia assimétrica de natureza e sociedade (funcionando como polos) é fruto de uma ilusória modernidade. Assim, ao olharmos para um híbrido e analisarmos sua rede sociotécnica "podemos investigar e chegar a conclusões sobre o que é a sociedade e o que é a natureza do qual ele faz parte" (LIMA; OSTERMANN; CAVALCANTI, 2018, p. 384).

Nesses termos, as visões de Latour podem se aproximar de uma educação em ciências (que historicamente foi tangenciada por valores e temáticas sociais) ancorada 
nas relações CTS (ciência, tecnologia e sociedade), que reforçam as discussões sobre a natureza da ciência, aproximando-se das Ciências Humanas e Sociais, acentuando o conhecimento científico como construção proveniente de relações humanas e nãohumanas e não como "verdade natural e absoluta". Lima, Ostermann e Cavalcanti (2018) sinalizam algumas reflexões nesse sentido, relacionando implicações da visão de Latour para a educação em ciências na "abordagem da ciência em ação", na "preocupação com o processo de formação das teorias científicas e não somente a apresentação das teorias 'prontas", na "problematização das redes sociotécnicas" e na "formação de uma comunidade de leitores escritores" (p. 367).

Partindo dessas implicações, Lima, Ostermann e Cavalcanti (2018) sugerem uma significativa revisão dos objetivos, dos conteúdos e dos métodos aplicados no ensino de ciências. Nessa convergência, acrescentamos as discussões de Candau (1982, 2016) acerca dos processos tradicionais de formação de professores, uma vez que essa significativa revisão pressupõe um olhar multidimensional à educação e, consequentemente, à formação de professores de ciências. A autora destaca como essencial a construção de uma visão integrada das dimensões humana, técnica e político-social, "partindo-se de uma perspectiva de educação como prática social inserida num contexto político-social determinado, no entanto não são deixadas num segundo plano as variáveis processuais" (CANDAU, 1982, p.23).

Ao pensarmos o ensino de ciências como um processo de formação científica eminente ao exercício dos direitos e deveres políticos, sociais e ambientais por parte dos indivíduos que compõem uma nação, entendemos como primordial um olhar para o espaço educacional, guarnecido de relações sociais cotidianas. Nesses espaços são produzidos e compartilhados domínios como a identidade, o discurso, a representação e a prática, dentre outros (JOVCHELOVITCH, 2004). Partindo de uma perspectiva psicossocial, os estudos de RS fornecem instrumentos que podem sinalizar as práticas de um grupo pela via de seus mecanismos representacionais (CAMPOS, 2017). No entendimento das práticas sociais apresentado por Campos (2017), ${ }^{3}$ identificamos a ação como uma referência básica, possuindo, esta, três componentes básicos: o comportamental, o afetivo e o cognitivo. Assim, pela natureza cognitiva dos estudos das representações, é possível, também, reflexionar as ações de um grupo de professores por esta via.

Logo, a importância de conhecer as RS que os professores constroem sobre o objeto deste estudo está relacionada ao fato de elas darem sentido a suas ações, pois estas são guiadas pelo conjunto de conhecimentos elaborados em relação à situação ou ao objeto com o qual se interagem. Por esse motivo, quando há interesse em conhecer como os professores reconhecem e colocam em prática o ensino de ciências, é fundamental explorar o conteúdo representacional acerca deste. Assim sendo, esses preceitos nos encaminharam aos referencias teóricometodológicos discutidos a seguir.

\subsection{0 s estudos de Representações Sociais e o campo educacional}

A Teoria das Representações Sociais (doravante TRS) foi implementada pelo psicólogo social Serge Moscovici em seu trabalho de doutoramento "La Psychanalyse, son image et son public", divulgado em 1961, quando estruturou 
relações entre conceitos da Psicologia e da Sociologia, restaurando a noção de Representações Coletivas descrita por Émile Durkheim (MOSCOVICI, 2012). $\mathrm{Na}$ ocasião de sua pesquisa, investigou como a psicanálise era representada pela comunidade parisiense, com o interesse de compreender quais mecanismos eram executados na tarefa de apreensão desse conceito científico por distintos grupos sociais. Em sua concepção, tratou as RS como manifestações particulares que compõem o senso comum e produzem uma determinada realidade, guiando a comunicação e as ações dos indivíduos (MOSCOVICI, 2012). Elas orientam a exploração dos fatos cotidianos, convergindo na produção de um tipo de saber funcional que tem por finalidade transpor algo incomum em algo usual.

Segundo Moscovici (2012), a operacionalização do pensamento humano se dá por dois mecanismos sociais distintos, que ele trata como universos "reificado" e "consensual". Esses mecanismos são guiados por objetivos variados, sendo, o primeiro, materializado no espaço científico, onde a ciência é a responsável pela orientação da realidade, independente da consciência dos indivíduos. O segundo se caracteriza pelas trocas cotidianas, onde cada sujeito é tido como um ser capaz de responder por seu grupo sob seu auspício. Nesse contexto, as RS podem ser produzidas, ou até mesmo reestruturadas, por meio do processamento da memória (transformar a informação abstrata em algo concreto - objetivação) e da busca de experiências envolvendo o objeto pouco conhecido (ajustar essa novidade a um contexto já habitual - ancoragem) (MOSCOVICI, 2012). Decerto, então, pode-se afirmar que uma RS possui uma estruturação de natureza dupla: uma figurativa e outra conceitual, ambas promovendo, em relação ao objeto representado, a referência de sua imagem à sua significação, atribuindo-lhe tangibilidade e permitindo-lhe acepção mesmo em sua ausência (MOSCOVICI, 2012). E, enquanto formas de conhecimento prático, as RS assumem outras aplicações, além da já mencionada familiarização com a novidade (função cognitiva), a saber: "orientação das condutas e das comunicações (função social); proteção e legitimação de identidades sociais (função afetiva)" (SPINK, 1993, p. 306).

Desde sua formulação, a TRS tem sido empregada por diferentes áreas de estudos, o que tem permitido múltiplos olhares para as suas definições e fomentado distintas contribuições à teoria, que vão "desde a perspectiva psicologista da cognição social até a perspectiva sociologista das representações coletivas" (SA, 1998, p.63-64). Estas configuram tratamentos complementares à TRS. Sobressaem-se, apoiadas na "escola moscoviciana" ou em seus desdobramentos, as abordagens de perspectiva antropológica, de perspectiva sociológica e as que privilegiam as características cognitivo-estruturais, que serão tratadas com maior amplitude pelo interesse do presente trabalho.

A abordagem estrutural contou com os estudos desenvolvidos por Jean-Claude Abric, que investigavam as propriedades cognitivo-estruturais de RS e fomentaram a elaboração da Teoria do Núcleo Central (doravante TNC) (SÁ, 1996). De acordo com essa teoria, "uma representação é composta de um conteúdo e de uma organização ou estrutura, essa última dividida em dois sistemas (núcleo central e elementos periféricos), cada um assegurando diferentes funções" (CAMPOS, 2017, p. 790). Os componentes dessa estrutura possuem papéis específicos, porém contingentes: o "sistema central (o núcleo 
central), cuja determinação é essencialmente social, ligada às condições históricas, sociológicas e ideológicas" (ABRIC, 1998, p. 33), é congruente a um compêndio de valores e normas, que atribui particularidade e significação à RS; e o "sistema periférico, $[\ldots]$ associado às características individuais e ao contexto imediato e contingente, nos quais os indivíduos estão inseridos" (ABRIC, 1998, p. 33). Nessa acepção, as enunciações relativas à organização estrutural de uma representação procuraram aclarar duas de suas características, aparentemente contraditórias: "as representações sociais são ao mesmo tempo estáveis e móveis, rígidas e flexíveis" e "as representações sociais são consensuais, mas também marcadas por fortes diferenças interindividuais” (ABRIC, 1993, p. 75).

No curso do desenvolvimento da TNC alguns especialistas contribuíram na elaboração de métodos para o levantamento do conteúdo das RS e reconhecimento do provável NC, apresentando destaque o trabalho de Pierre Vergès (SÁ, 1996). $\mathrm{O}$ método proposto por Vergès articula algumas características de evocações emitidas com base em um termo gerador, associado ao objeto da representação. As metodologias de trabalho produzidas nesse sentido, como destaca Sá (1996), por mais objetivas e ponderadas que sejam, não configuram suficientemente a percepção global de uma RS, porém, na inexistência dessas, "abre-se um perigoso espaço para avaliações meramente impressionistas da importância relativa das diferentes cognições para a organização da representação" (p. 177), sendo sua observância associada às primeiras fases de uma abordagem plurimetodológica nos estudos de RS (SÁ, 1996).

No conjunto de aportes fornecidos pelos estudos de RS, acentuam-se os que tangem o âmbito educacional. As produções de Gilly (2002), Alves-Mazzotti (2008), Ornellas (2009), Chaib (2015), dentre numerosas outras de equivalente teor, sinalizam que a TRS e suas contingentes complementações se manifestam como instrumentos valiosos para investigações de variadas questões relacionadas à educação. Segundo Gilly (2002), a noção de RS nesse campo de pesquisas, independente de seus olhares, "orienta a atenção sobre o papel de conjuntos organizados de significações sociais no processo educativo” (p. 232), o que favorece uma associação entre a psicossociologia e sociologia da educação. Nesse contexto, desferem-se investigações de fenômenos que vão desde ligações a um determinado grupo social, à compreensão de atitudes e valores tangentes à escola, à forma como os integrantes do espaço escolar concebem seu papel, até às conjunções interpretativas relativas à comunicação didática nessa esfera e à produção dos diferentes saberes disciplinares (ALVES-MAZZOTTI, 2008; GILLY, 2002).

Em precedente pesquisa realizada no cenário nacional, Vittorazzi (2018) sinaliza crescente o quantitativo de produções, entre os anos 2000 e 2015, na interface entre estudos de RS e as áreas das Ciências Humanas e Multidisciplinar/ Ensino. Nesta última, o Ensino de Ciências apresentou relevantes contribuições com maior foco nos temas tratados pela Biologia, principalmente os que concernem as "interações entre os seres vivos". No contexto do Ensino de Ciências, as pesquisas relacionaram, de modo comum, a importância das estruturas sociocognitivas (ou RS) nos processos de construção do conhecimento "formal" no espaço escolar, com vistas à formação para a cidadania, uma vez que "trabalharam com elementos que caracterizam o pensar e o agir social e sinalizaram, para tanto, caminhos para a compreensão e o envolvimento em 
questões sociais, políticas, econômicas, culturais e ambientais" (VITTORAZZI, 2018, p.74) assentadas no ensino de ciências e seus processos formativos.

Para Campos (2017), dentre as provocações mais atuais da área estaria o estudo da ancoragem como meio de acesso aos sistemas sociocognitivos vinculados ao contexto escolar, sendo fundamentais, para tanto, exames que ultrapassem o caráter narrativo das RS e alteiem à interpretação ativa dos elementos psicossociais que integram a construção da função social da escola e de seus protagonistas.

Os preceitos aqui descritos se constituem em referências teóricometodológicas ajustadas aos objetivos propostos neste trabalho, os quais caracterizam um diagnóstico introdutivo ao tema "o ensino de ciências para professores do Ensino Fundamental". Pretende-se, nesse contexto, que as propostas deste estudo caminhem consoantes aos inquéritos que permeiam reflexões acerca dos fatores que compreendem as relações entre os indivíduos e os grupos aos quais pertencem, fornecendo importantes contribuições a uma interlocução interdisciplinar aos temas sociocientíficos.

\section{METODOLOGIA DA PESQUISA}

O presente trabalho, de cunho qualitativo, partiu de suas bases teóricometodológicas para a seleção de instrumentos de coleta e análise de dados. A TRS e as contingentes contribuições da TNC não privilegiam nenhum método específico em seus estudos, porém, a literatura especializada sinaliza para procedimentos de inquérito e evocação livre de palavras na coleta de dados empíricos, quando os interesses da pesquisa se concentrarem nas primeiras etapas da abordagem plurimetodológica aludida por Abric, as quais compreendem o levantamento do conteúdo representacional e a sua estrutura organizacional (SÁ, 1996).

Utilizamos, a partir dessa premissa, um questionário com questões fechadas para a caracterização do grupo, itens para a evocação e hierarquização livres de palavras assentes no termo indutor "Ensinar Ciências" e quesitos para descrição espontânea sobre o tema. Os dados coletados, no interesse da exploração do espectro representacional do objeto em questão, foram analisados a partir dos preceitos da Análise de Conteúdo (BARDIN, 1977), por meio da categorização dos temas identificados nos discursos produzidos pelos docentes. Os dados evocados e hierarquizados pelos sujeitos foram homogeneizados e processados com o auxílio dos softwares Evocation (Evoc) ${ }^{4}$ e Iramuteq ${ }^{5}$ na diligência do levantamento dos prováveis elementos estruturais da RS, seguindo os investimentos de Pierre Vergès, baseados na abordagem estrutural recomendada pela TNC (SÁ, 1996; VERGÈS, 2001).

A Análise de Conteúdo é tratada como um conjunto de técnicas que permitem a interpretação de comunicações por meio da obtenção de indicadores, quantitativos ou não, caracterizados em tópicos que possibilitam implicações a respeito das condições de gênese ou acolhida das mensagens (BARDIN, 1977). Pelo caráter híbrido (quantidade/qualidade) da técnica (BAUER, 2002), identificamos o conteúdo relacionado aos eixos temáticos expressos nos depoimentos escritos pelos professores, propiciando o conhecimento da materialidade de suas RS.

$\mathrm{O}$ método de descrição dos elementos do NC, preconizado por Vergès, relaciona "a frequência de emissão das palavras e/ou expressões com a ordem 
em que estas são evocadas" (SÁ, 1996, p. 116), além da sugestão de análise das relações existentes entre os termos como meio de reiterar a composição desse sistema, sendo possível a produção de categorias para inferências quanto a sua organização. Assim, no presente estudo, adotamos tais métodos para a sondagem dos elementos centrais da RS, visto seu caráter prototípico (correspondente à evidência) e símile (correspondente à conexidade) (SÁ, 1996).

A distribuição dos elementos nos setores central e periféricos da RS, realizada por intermédio da análise prototípica, resultou na construção do quadrante de Vergès (Figura 1). Neste, o software Evocation organizou os termos evocados em quatro áreas, produzidas pelo cruzamento de suas frequências com a ordem média de suas evocações. $\mathrm{Na} 1^{\mathrm{a}}$ área do quadrante, foram alocados os elementos mais frequentes e mais prontamente evocados; na $2^{a}$, os elementos com elevada frequência, porém evocações mais tardias do que as que compõem a $1^{a}$ área; na $3^{a}$, os que apresentavam baixa frequência, porém considerados pertinentes pelos professores; e na $4^{\mathrm{a}}$, os termos com baixa regularidade e evocados de modo remanescente (SÁ, 1996).

Figura 1. Quadrante de Vergès

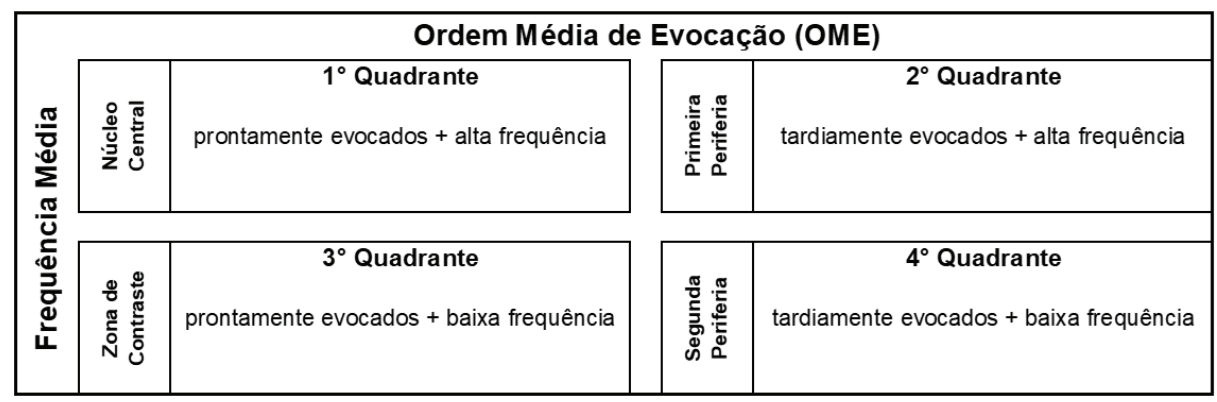

Fonte: Organizado pelos autores a partir de Sá (1996).

A verificação da centralidade dos elementos em uma RS, inicialmente realizada pela análise prototípica, segundo Vogel (2016, p. 108), pode ser "complementada pela análise de similitude do termo, confirmando sua centralidade, por um processo de análise de co-ocorrências que indica a conexidade". Empregamos, por meio do software Iramuteq, a enumeração dos índices de similitude entre os termos que apresentavam frequência significativa, resultando na construção de uma "árvore máxima que sintetiza, graficamente, o conjunto das conexões existentes entre tais termos" (VOGEL, 2016, p. 108). De acordo com Sá (1996), a análise de similitude foi entabulada no campo dos estudos de RS nos anos setenta do século XX por Claude Flament, com o préstimo de outros pesquisadores, tornando-se a "principal técnica de detecção do grau de conexidade dos diversos elementos de uma representação" (p. 126).

Com atenção aos parâmetros éticos e científicos descritos em regulamentações nacionais, todos os vinte participantes, professores de ciências da natureza das séries iniciais e finais do Ensino Fundamental de um município do Estado do Espírito Santo, foram esclarecidos quanto à natureza da pesquisa, seus objetivos e métodos, os riscos e relevância de sua colaboração, sendo sua concordância registrada em Termo 
de Consentimento Livre e Esclarecido (TCLE). Em consideração ao prescrito, os sujeitos foram identificados pela denominação "P”" seguida de número de ordem "01, $02,03, \ldots, 20$ ” no intuito de preservar suas identidades. Pretendemos, pela escolha do grupo participante, alcançar professores que se ocupavam diretamente com o objeto do presente estudo, tendo representatividade positiva, seu município de atuação, nos resultados do Programa de Avaliação da Educação Básica do Espírito Santo ciências da natureza, em sua $16^{\mathrm{a}}$ edição.

\section{ANÁLISE E DISCUSSÃO DOS RESULTADOS}

\subsection{Os sujeitos da pesquisa}

No presente estudo participaram vinte professores, sendo declarados $90 \%$ do gênero feminino e 10\% do gênero masculino. A assimetria acerca do gênero indicado pelos participantes coincide com estatísticas nacional e estadual apontadas pelo MEC/Inep (2007), quando relataram a existência, no Brasil, de $81,94 \%$ de professores da Educação Básica pertencentes ao gênero feminino e 18,06\% ao gênero masculino; e no Espírito Santo, o quantitativo de 82,93\% de professores do gênero feminino e $17,07 \%$ do gênero masculino. Dentre os diversos fatores que contribuem para os resultados, André (2002) destaca o imaginário social que caracteriza uma associação entre escola e maternidade, o que permite a concepção do processo educativo como um seguimento do lar, onde as mulheres normalmente assumem sua coordenação. As professoras tratadas como "tias", nos espaços escolares, refletem a relação dessas profissionais com uma figura familiar próxima à materna.

Os dados levantados sobre a formação dos professores da pesquisa revelaram que todos possuem formação adequada para atuarem na Educação Básica, conforme legislação vigente. Os 85\% dos professores, que representam os atuantes nos anos iniciais do Ensino Fundamental, possuem Licenciatura na área das Ciências Humanas - Pedagogia; os 15\% dos professores, que correspondem aos atuantes nos anos finais, possuem Licenciatura na área das Ciências Biológicas Biologia Geral. Vale ressaltar que, conforme determinação da Secretaria de Estado da Educação do Espírito Santo, a formação básica exigida ao professor para lecionar ciências da natureza nas séries finais do Ensino Fundamental equivale ao curso de Licenciatura em Ciências Biológicas/ Biologia, o que justifica a presença de apenas profissionais, atuantes nessas classes, licenciados nessa área na presente pesquisa.

\subsection{0 conteúdo cognitivo-estrutural das representações sociais}

A construção da análise prototípica deu-se por meio da definição de alguns critérios fundamentais (WACHELKE; WOLTER, 2011). O primeiro refere-se ao valor da frequência de corte $(\mathrm{FC})$, que indica ao software Evocation qual será a menor frequência a ser considerada para a disposição dos termos no quadrante, excluindo os menos citados, por serem pouco significativos; o segundo ocupa-se do valor da média geral de ordenamento das evocações (MGOE) das palavras, que é obtido por via da média dos pesos atribuídos às evocações; e o terceiro 
compreende o valor da frequência mediana (FM), produzido mediante o cômputo da mediana das frequências após o descarte dos valores menores que a frequência mínima considerada. Por meio da inserção dos dados no Evocation, obtivemos os seguintes valores: $\mathrm{FC}=2, \mathrm{MGOE}=3,00$ e $\mathrm{FM}=5$.

Fixados estes parâmetros, seguimos à produção do quadrante de Vergès (Figura 2). O quadrante traz uma distribuição dos prováveis elementos da representação do ensino de ciências do grupo de professores em questão, baseando-se na relação entre a frequência e ordem média dos termos evocados (WACHELKE e WOLTER, 2011). No $1^{\circ}$ quadrante, representando o NC, foram alocados os termos CONHECIMENTO, LEITURA e OBSERVAÇÃO por terem sido frequentemente citados, estando entre os primeiros termos hierarquizados pelo grupo. Segundo a TNC, a representação em questão é organizada em torno desses elementos, os quais lhe atribuem significado. Esse conjunto está ligado à memória coletiva e à história do grupo, é estável, coerente e rígido e define sua homogeneidade, visto sua elevada frequência e relevância no composto de evocações e, por consequência, é muito resistente a mudanças (ABRIC, 1993).

Figura 2. Quadrante de Vergès - elementos estruturais da RS do ensino de ciências

\begin{tabular}{|c|c|c|c|c|c|c|c|c|}
\hline \multirow{5}{*}{ 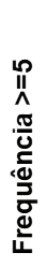 } & \multicolumn{4}{|c|}{ OME $<=3,00$} & \multicolumn{4}{|c|}{ OME $>=3,00$} \\
\hline & \multirow{4}{*}{ 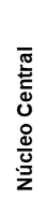 } & Termos & f & OME & \multirow{4}{*}{ 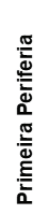 } & Termos & $f$ & OME \\
\hline & & CONHECIMENTO & 10 & 2,100 & & EXPERIENCIA & 7 & 4,286 \\
\hline & & LEITURA & 5 & 2,400 & & PESQUISA & 10 & 3,100 \\
\hline & & OBSERVACAO & 6 & 1,833 & & SERES_VIVOS & 6 & 3,333 \\
\hline \multirow{7}{*}{ 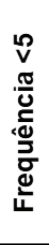 } & \multirow{7}{*}{ 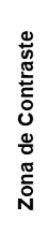 } & Termos & $f$ & OME & \multirow{7}{*}{ 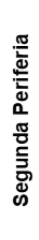 } & Termos & $f$ & OME \\
\hline & & CORPO_HUMANO & 3 & 2,667 & & APRENDER_MAIS & 4 & 3,500 \\
\hline & & CURIOSIDADE & 3 & 3,000 & & AULA_PRATICA & 4 & 4,500 \\
\hline & & DESCOBERTA & 2 & 2,000 & & PROJETOS & 2 & 3,500 \\
\hline & & ESTAR_INFORMADO & 2 & 3,000 & & & & \\
\hline & & ESTUDO & 3 & 2,667 & & & & \\
\hline & & MEIO_AMBIENTE & 4 & 2,000 & & & & \\
\hline
\end{tabular}

Fonte: Organizado pelos autores.

$\mathrm{Na}$ primeira periferia, encontramos os termos EXPERIÊNCIA, PESQUISA e SERES VIVOS. Esses elementos situam-se mais próximos ao $\mathrm{NC}$ e, no sistema periférico, tornam-se mais importantes por terem sido frequentemente evocados, porém ocupando ordens posteriores aos termos do NC. $\mathrm{Na}$ zona de contraste figuram os termos CORPO HUMANO, CURIOSIDADE, DESCOBERTA, ESTAR INFORMADO, ESTUDO e MEIO AMBIENTE. São termos que possuem baixa frequência, porém apresentam destaque na posição hierárquica das evocações. Normalmente complementam os elementos da primeira periferia (ABRIC, 1998; SÁ, 1996). A segunda periferia é provavelmente composta pelos termos APRENDER MAIS, AULA PRÁTICA e PROJETOS. São palavras 
tardiamente evocadas e com baixa frequência, o que as aproxima de experiências de caráter restrito aos indivíduos do grupo (ABRIC, 1998; SÁ, 1996).

A produção do gráfico de similitude máxima dos termos da RS do ensino de ciências partiu do interesse de evidenciar as relações estabelecidas entre esses elementos. Para a análise de similitude adotamos, como a exemplo do procedimento citado no estudo prototípico, a exclusão dos termos de baixa frequência. Na Figura 3 é possível considerar que os termos CONHECIMENTO, EXPERIÊNCIA, LEITURA, OBSERVAÇÃO e PESQUISA apresentam maior conexidade, visto seu maior número de arestas e alto valor de co-ocorrências. Dentro desse grupo de palavras, localizam-se as que, segundo o quadrante de Vergès, compõem o provável NC da representação.

Figura 3. Árvore máxima de similitude para os termos da RS do ensino de ciências

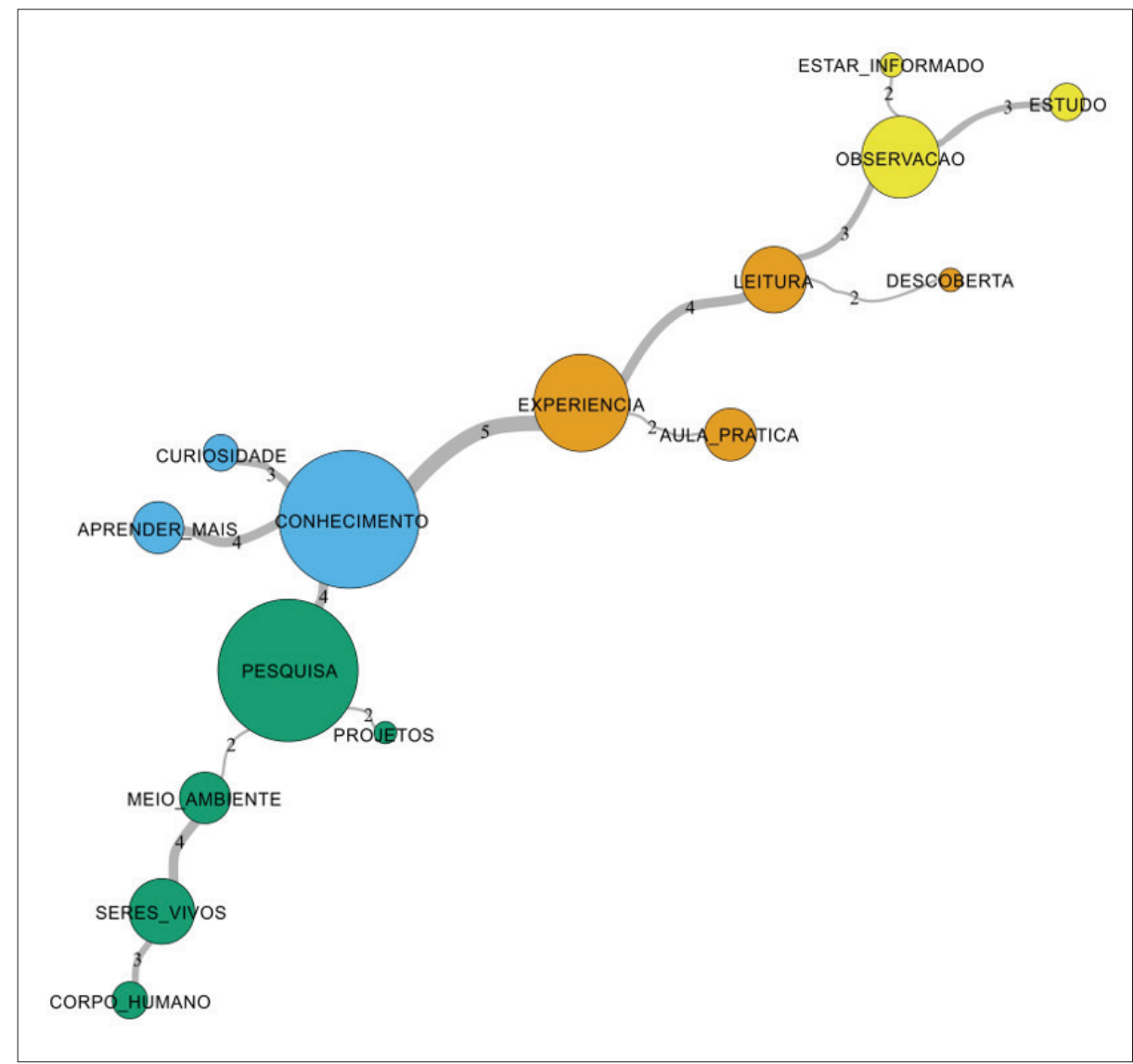

Fonte: Organizado pelos autores.

Podemos, dessa forma, acentuar a evidência de que os termos CONHECIMENTO, LEITURA e OBSERVAÇÃO compõem o núcleo central 
da RS do ensino de ciências, uma vez que apresentam alto valor simbólico (tratado na relação entre frequência e ordem média de evocação) e alto poder associativo (tratado na relação entre a quantidade de arestas e co-ocorrências).

Destacamos que, assumindo os mecanismos de objetivação e ancoragem como macroprocessos complementares que, segundo Moscovici (2012), explicam a formação e transformação das representações, podemos presumir que o grupo de professores, ao compararem o objeto ensino de ciências às referências de uma categoria, os reajustam de acordo com as características dessa esfera para que se adequem a ela. Ou seja, mesmo os professores já possuindo parcelas de conhecimento científico, possivelmente construídas em seus processos de formação, estas podem ser reestruturadas, ou até mesmo produzidas na ocasião de sua inexistência, quando enquadradas em padrões socialmente elaborados, como, por exemplo, as visões de mundo ou concepções prévias ou alternativas da produção científica, os modos tradicionais de ensino e as discussões CTS. Esse fato pode ser sinalizado ao notarmos aproximações entre as RS assinaladas neste trabalho com características dos padrões amplamente difundidos socialmente, neste parágrafo citados.

Assim, no interesse de percebermos como os termos da RS do ensino de ciências se comportam quanto à sua significação, empregamos técnicas de Análise de Conteúdo (BARDIN, 1977). No Quadro 1 foram dispostos os termos da RS, conforme sua estruturação e categorização.

Quadro 1. Categorização dos termos da RS do ensino de ciências

\begin{tabular}{|c|c|c|c|c|}
\hline \multirow{2}{*}{\begin{tabular}{c} 
Categorias $\begin{array}{l}\text { Unidades de } \\
\text { registro }\end{array}$ \\
\cline { 2 - 5 } Conteúdos
\end{tabular}} & Núcleo central & Primeira periferia & Zona de contraste & Segunda periferia \\
\cline { 2 - 5 } & - & SERES VIVOS & $\begin{array}{c}\text { CORPO HUMANO } \\
\text { MEIO AMBIENTE }\end{array}$ & - \\
\hline Procedimentos & $\begin{array}{c}\text { LEITURA } \\
\text { OBSERVAÇÃO }\end{array}$ & $\begin{array}{c}\text { EXPERIÊNCIA } \\
\text { PESQUISA }\end{array}$ & ESTUDO & $\begin{array}{c}\text { AULA PRÁTICA } \\
\text { PROJETOS }\end{array}$ \\
\hline Implicações & CONHECIMENTO & - & $\begin{array}{c}\text { CURIOSIDADE } \\
\text { DESCOBERTA }\end{array}$ & APRENDER MAIS \\
& ESTAR INFORMADO & \\
\hline
\end{tabular}

Fonte: Organizado pelos autores.

O ensino de ciências é amplamente representado pelo termo CONHECIMENTO, componente do NC da RS, que se fez marcante, também, no discurso dos professores acerca do que é ensinar ciências. Assenta-se nos discursos de P01, quando afirma que o ensino de ciências é importante, pois " $a$ ciência ajuda o homem ao longo do tempo a alcançar os conhecimentos do mundo que os rodeiam e também a sua própria individualidade"; de P05, "para que o aluno tenha novas abordagens de conhecimento"; de P07, "ensinar ciências é muito importante para um estudo mais avançado, para o conbecimento e para tecnologia"; de P16, "ela [a ciência] é um conhecimento que colabora para que o indivíduo compreenda o mundo em que vive e as transformações que nele ocorrem, sendo o individuo parte desse mundo"; de P17, "faz com que os alunos aprendam os conbecimentos cientificos e os coloquem em prática". 
Notamos, neste caso, uma proximidade entre a centralidade do termo na RS com as noções de que o conhecimento real e sistemático é produzido pela ciência e este, pela ideia popular que o caracteriza com um bem comum, deve ser ensinado para os cidadãos em sua lógica formativa (GOLEMBEK, 2009). Estudos sobre a construção histórica das disciplinas escolares revelam que todo conhecimento socialmente expressivo deve ser aprendido e, para tanto, necessita ser ensinado e, à vista disso, se constitui em disciplina escolar, por meio de procedimentos de redimensionamento exercidos pela e para a escola (CHERVEL, 1990).

Os termos LEITURA e OBSERVAÇÃO, por suas vezes, apontam para procedimentos característicos dos processos de ensino, possivelmente gravados na cultura escolar. ${ }^{6}$ Ou seja, "fazer com que o aluno observe, pesquise em diversas fontes, questione e registre" (P15) são caminhos para se aprender ciências na escola. Esses termos (LEITURA e OBSERVAÇÃO) podem trazer vínculos com questões metodológicas do ensino de ciências. Bizzo (2012) apresenta uma importante reflexão acerca das relações entre metodologias de ensino e técnicas de ensino, assinalando a importância da não dissociação entre os encargos do professor e dos alunos, sendo, a metodologia, diretamente fundamentada nessas interações. Para o autor, as metodologias de ensino podem ser configuradas a partir de algumas dimensões básicas, as quais concretizam o ato educativo, envolvendo questões epistemológicas dos processos de ensinar e aprender e institucionais, ligadas ao arranjo político-social da escola. Nesse contexto, evidencia a importância dimensional das imagens do professor e do aluno, as quais devem ser profundamente refletidas na construção do projeto político-pedagógico escolar.

Nesse âmbito, destacam-se procedimentos baseados na problematização das tarefas escolares, que envolvem um olhar para o ensino de ciências com base na investigação (CAMPOS; NIGRO, 2009; POZO; CRESPO, 2009; SCHIEL; ORLANDI, 2009). Para os autores, considerando-se que a educação científica deve capacitar o indivíduo a uma atuação prática, cívica e cultural, esta deve se estear "não apenas na aquisição de conhecimentos científicos (fatos, conceitos e teorias), mas no desenvolvimento de habilidades a partir da familiarização com os procedimentos científicos, na resolução de problemas, na utilização de instrumentos e, por fim, na aplicação em situações reais do cotidiano" (SCHIEL; ORLANDI, 2009, p. 9).

No enquadramento do ensino por investigação, o professor se afasta do papel de "transmissor de conhecimentos" e o aluno se aproxima do papel de "investigador", despertando um olhar não superficial para os fenômenos do mundo (CAMPOS; NIGRO, 2009). Os termos centrais, destacados no parágrafo precedente, podem não estar ajustados a esses papéis, revelando caminhos metodológicos baseados em concepções mais tradicionais de ensinar e aprender.

No entanto, para Latour e Woolgar (1997), o trabalho científico se caracteriza por diferentes elementos e, dentre estes, destaca-se o modo particular de produção textual. Tais referências também podem se relacionar aos termos LEITURA e OBSERVAÇÃO. Destacamos que uma das habilidades a serem desenvolvidas por meio do ensino de ciências, atualmente, refere-se à capacidade de ler, interpretar e produzir textos argumentativos e explicativos, dominando-se, para tanto, instrumentos básicos da linguagem científica (ESPÍRITO SANTO, 2009). Lima, Ostermann e Cavalcanti (2018) salientam a relevância desse objetivo, 
atentando para, na prática da leitura e escrita científica, não se recobrar a ideia de ciência objetiva, neutra e universal. Reportamos que uma análise das ações docentes do grupo seria indicada para verificar essas hipóteses.

Os sistemas periféricos da RS do ensino de ciências trazem elementos que representam conteúdos da disciplina ciências, como SERES VIVOS, CORPO HUMANO, MEIO AMBIENTE, e procedimentos característicos de metodologias de ensino, como AULA PRÁTICA e PROJETOS. Quanto aos conteúdos, é possível perceber sua presença nos manuais que orientam o ensino de ciências da natureza, em todas as séries do Ensino Fundamental, o que assinala as experiências individuais e heterogêneas dos professores.

Para Pozo e Crespo (2009), a aprendizagem dos conceitos científicos é um traço marcante no ensino de ciências. Tal característica também advém de concepções tradicionais do processo de ensinar e aprender e se fazem presentes, em maior ou menor grau, nos discursos de professores, nos manuais e propostas pedagógicas destinadas à disciplina. Não é de interesse da presente pesquisa, porém, um julgamento valorativo dessas relações, mas sim sinalizar para considerações da medida que esses aspectos devem assumir nesses processos, quando se pretende que o ensino de ciências contribua na alfabetização científica que ultrapasse os estágios nominais e funcionais, atingindo etapas estruturais ou, até mesmo, multidimensionais (KRASILCHIK; MARANDINO, 2007).

Ao contexto dos livros e manuais de ciências, destacamos que estes normalmente funcionam como instrumentos de perpetuação de visões soberanas acerca dos fatos científicos (KUHN, 1998). Neste sentido, vale destacar que toda produção científica advém de um processo permeado por interesses e relações de diferentes naturezas e atores, convergindo no que Latour (1994) denomina de híbridos. Para o autor, os resultados dos trabalhos dos cientistas são interpretações permeadas pelo uso de equipamentos sob o auspício de argumentações científicas e políticas. Essas interações configuram uma rede de atores (humanos e não-humanos) que conduz à produção do conhecimento científico. Por essa rede, a sociedade e a natureza são construídas conjuntamente. Nesse sentido, utilizando a proposta de híbridos, é significativo perceber que os fatos científicos, que por muitas vezes são introduzidos por um discurso didático que enfatiza a ideia de descoberta individual, são produzidos por um conjunto de relações heterogêneas. Há a necessidade, no interesse de um olhar mais atento para os objetos científicos e seus impactos, como nos sugerem Lima, Ostermann e Cavalcanti (2018), de considerarmos os processos e não apenas os produtos, abandonando mitos de gênios e verdades absolutas.

Quanto aos métodos de ensino, caracterizados pelos termos mais periféricos, estes podem qualificar os contextos mais imediatos provenientes das correntes metodológicas mais tratadas pelo grupo. O contexto das redes sociotécnicas também pode ser aplicado a esta análise, uma vez que a produção e a utilização desses métodos se dão pelo coletivo de pessoas e instrumentos em intercâmbio de ideias. Destacamos, reiterando a ideia de redes, que o documento norteador da Educação Básica no Espírito Santo sinaliza a importância de alguns princípios metodológicos no ensino de ciências, dentre os quais a interdisciplinaridade, no sentido de estabelecer diálogos entre as diferentes disciplinas com o objetivo de integrar conhecimentos, o que pode se concretizar na 
forma de projetos (PROJETOS); e a experimentação, orientando a realização de aulas práticas (AULAS PRÁTICAS) para que investiguem e busquem explicações para os fenômenos naturais (ESPÍRITO SANTO, 2009). Esta análise pode nos encaminhar a reflexões sobre questões de caráter curricular e tal perspectiva pode se configurar em roteiros complementares a esta pesquisa, permitindo um olhar para os documentos curriculares e suas implementações em um âmbito mais amplo (a exemplo da nova Base Nacional Comum Curricular).

Os termos periféricos CURIOSIDADE, DESCOBERTA, ESTAR INFORMADO e APRENDER MAIS podem estar relacionados, como sugerimos na produção de nossas categorias, com as implicações do ensino de ciências. Ou seja, para os professores o ensino é importante, pois estimula "descobertas e a aproximação da prática da curiosidade" (P06), encaminha o "conbecimento que colabora para que o individuo compreenda o mundo em que vive e as transformações que nele ocorrem, sendo o indivíduo parte desse mundo" (P18). Retomamos, nesse sentido, algumas reflexões acerca da ideia de alfabetização científica, sinalizando que esta deve carregar os princípios de letramento. A informação, por meio da prática experimental, da curiosidade, da leitura ou da observação, deve encaminhar a produção de conhecimento que permita a compreensão de fenômenos em seu contexto histórico-social e a participação na cultura científica de modo individual ou coletivo (KRASILCHIK; MARANDINO, 2007).

Nesse contexto, entendemos relevantes algumas reflexões acerca dos modelos de comunicação pública da ciência utilizados nos espaços escolares. Krasilchik e Marandino (2007, p. 35) sinalizam que "a percepção de que o conhecimento científico é verdadeiro, imune a questionamentos e distante das demandas da população geral, ainda é fortemente presente", acarretando a configuração de algumas formas de divulgar esse conhecimento. Longe de discutir vantagens e desvantagens de cada uma, pretendemos, neste ponto, trazer a relevância da reflexão docente na busca de mecanismos que focalizem não somente a apropriação de conhecimentos, mas que possibilitem a articulação com saberes locais e a sua aplicação nos contextos científicos e tecnológicos.

\section{CONSIDERAC̣ÕES FINAIS}

Este estudo buscou conhecer como os professores do Ensino Fundamental representam o ensino de ciências e, nesta tarefa, por meio da aplicação do referencial teórico-metodológico das RS, foi possível perceber elementos que caracterizam o ensino como a tarefa de ensinar conceitos e procedimentos relativos às ciências. Incumbência que não foge às determinações dos manuais que orientam a prática docente, mas que, por si só, não garantem uma alfabetização científica que permita compreender o modo de produzir ciência para que se possa utilizar e intervir na configuração social desse conhecimento.

No encargo de "ensinar" reside, além de conhecer os conteúdos da disciplina e seus métodos por parte do professor, o exercício de reflexão acerca das ideias de senso comum sobre o próprio ensinar e aprender e, também, sobre o objeto do ensino. Na tarefa de aprender ciências, sob um olhar socioconstrutivista, o aluno necessita de mediadores, papel este que pode se enquadrar ao professor. 
Esse "aprender ciências" passa pelo crivo de perceber que o conhecimento científico é socialmente negociado na empreitada de interpretar os fenômenos da natureza. Desse modo, para ensinar e aprender ciências é necessário o envolvimento com as ideias e práticas da comunidade científica, tornando-as significativas no nível individual.

Retomamos, nessa circunstância, a necessidade de explorar os processos formativos para docência, no sentido de perceber seus vínculos com as questões político-sociais e culturais do país. Candau (1982) sinaliza atenção a esses sistemas formativos, uma vez que podem subsidiar, quando desguarnecidos de um olhar para as dimensões educacionais articuladas de forma dinâmica e coerente, a instrução de legítimos especialistas de conteúdo ou técnicos da educação. Reforçamos, assim, que a educação é um processo multidimensional e que a formação de professores também deve seguir nessa direção. Afinal, como pensar em uma formação científica para o exercício da cidadania sem considerar as demandas culturais, históricas, políticas e ambientais que se articulam à produção de conhecimento? Essas demandas possuem papel valorativo nas experiências humanas, o que enriquece o trabalho escolar na construção de uma sociedade mais inclusiva e equitativa.

Como caminho da presente pesquisa, adotamos a abordagem de levantamento do conteúdo cognitivo-estrutural das RS dos professores, o que possibilitou algumas reflexões como respostas para a questão inicial de trabalho. É preciso considerar, no entanto, a importância de uma abordagem de caráter epistemológico do objeto em questão. Esse tratamento envolve compreender os macroprocessos de objetivação e ancoragem em sua construção social. Esses desafios se constituem em possibilidades para um estudo mais amplo, o qual implicaria na demanda de uma análise de caráter histórico e ontológico.

\section{AGRADECIMENTOS}

A Prefeitura Municipal de Castelo - ES e a CAPES pelo apoio financeiro durante o desenvolvimento da presente pesquisa.

\section{REFERÊNCIAS}

ABRIC, J. C. A abordagem estrutural das representações sociais. In: MOREIRA, A. S. P.; OLIVEIRA, C. P. (org.). Estudos interdisciplinares de representação social. Goiânia: AB, 1998. p. 27-38.

ABRIC, J. C. Central system, peripheral system: their functions and roles in the dynamics of social representations. Papers on Social Representations - Textes sur lês Représentations Sociales, v. 2, p. 75-78, 1993. Disponível em: <http://psr.iscte-iul.pt/index.php/PSR/article/view/126/90>.

ALVES-MAZZOTTI, A. J. Representações sociais: aspectos teóricos e aplicações à educação. Revista Múltiplas Leituras, v.1, n. 1, p.18-43, jan./jun. 2008. Disponível em: <http://emaberto. inep.gov.br/index.php/emaberto/article/download/1944/1913>.

ANDRÉ, M. E. D. A. Formação de professores no Brasil (1990-1998) - Série Estado do Conhecimento, n. 6. Brasília: MEC/Inep/Comped, 2002. 
ARRUDA, J. P.; FLORES, P. R. A constituição da matemática como uma disciplina escolar no ensino primário do Colégio de Aplicação da Universidade Federal de Santa Catarina. Acta Scientiae, Canoas, v. 14, n. 1, p.27-39, jan./abr. 2012. Disponível em: <http://www.periodicos.ulbra.br/index. $\mathrm{php} / \mathrm{acta} /$ article/view/209/194>.

BARCELlOS, P. A. O.; AZEVEDO JUNIOR, S. M.; MUSIS, C. R.; BASTOS, H. F. B. N. As representações sociais dos professores e alunos da Escola Municipal Karla Patrícia, Recife, Pernambuco, sobre o manguezal. Ciência \& Educação, Bauru, v. 11, n. 2, p. 213-222, 2005. Disponível em: <http://www.scielo.br/pdf/ciedu/v11n2/04.pdf>.

BARDIN, L. Análise de conteúdo. Lisboa: Edições 70, 1977.

BAUER, M. W. Análise de conteúdo clássica: uma revisão. In: BAUER, M. W.; GASKELL, G. (org.). Pesquisa qualitativa com texto: imagem e som: um manual prático. Tradução de Pedrinho A. Guareschi. $2^{\mathrm{a}}$ ed. Petrópolis: Vozes, 2002. p.189-217.

BIZZO, N. Pensamento científico: a natureza da ciência no ensino fundamental. São Paulo: Melhoramentos, 2012.

CACHAPUZ, A.; GIL-PÉREZ, D.; PRAIA, A. M. P. C. J.; VILCHES, A. Importância da educação científica na sociedade atual. In: CACHAPUZ, A.; GIL-PÉREZ, D.; PRAIA, A. M. P. C. J.; VILCHES, A. (org.). A necessária renovação do ensino de ciências. São Paulo: Cortez, 2005. p.19-34.

CAMARGO, B. V.; JUSTO, A. M. Tutorial para uso do software de análise textual IRAMUTEQ. Florianópolis: LACCOS-UFSC, 2013. Disponível em: <http://www.iramuteq.org/documentation/ fichiers/tutoriel-en-portugais>.

CAMPOS, M. C. C.; NIGRO, R. G. Teoria e prática em ciência na escola: o ensino-aprendizagem como investigação. $1^{\mathrm{a}}$ ed. São Paulo: FTD, 2009.

CAMPOS, P. H. F. O estudo da ancoragem das Representações Sociais e o campo da Educação. R. Educ. Públ., Cuiabá, v. 26, n. 63, p. 775-797, set./dez. 2017. Disponível em: <http:// periodicoscientificos.ufmt.br/ojs/index.php/educacaopublica/article/view/4187/pdf>.

CANDAU, V. M. F. A formação de educadores: uma perspectiva multidimensional. Em Aberto, Brasília, v. 1, n. 8, p. 18-23, ago. 1982. Disponível em: <http://emaberto.inep.gov.br/index.php/ emaberto/article/view/1393/1367>.

CANDAU, V. M. F. Cotidiano escolar e práticas interculturais. Cadernos de Pesquisa, São Paulo, v.46, n.161, p.802-820, jul./set. 2016. Disponível em: <http://www.scielo.br/pdf/cp/v46n161/19805314-cp-46-161-00802.pdf>.

CHAIB, M. Representações sociais, subjetividade e aprendizagem. Cadernos de Pesquisa, v.45, n.156, p.358-372, abr./jun. 2015. Disponível em: <http://www.scielo.br/pdf/cp/v45n156/19805314-cp-45-156-00358.pdf>.

CHERVEL, A. História das disciplinas escolares: reflexões sobre um campo de pesquisa. Teoria \& Educação, Porto Alegre, n.2, p.177-229, 1990. Disponível em: <https://moodle.fct.unl.pt/ pluginfile.php/122510/mod_resource/content/0/Leituras/Chervel01.pdf > .

CUNHA, R. B. Alfabetização científica ou letramento científico? - interesses envolvidos nas interpretações da noção de scientific literacy. Revista Brasileira de Educação, Campinas, v. 22, n. 68, p.169-186, jan./mar. 2017. Disponível em: <http://www.scielo.br/scielo.php?script=sci_ arttext\&pid $=$ S1413-24782017000100169>. 
CUNHA, R. B. Alfabetização científica ou letramento científico? - interesses envolvidos nas interpretações da noção de scientific literacy. Revista Brasileira de Educação, Campinas, v. 22, n. 68, p.169-186, jan./mar. 2017. Disponível em: <http://www.scielo.br/pdf/rbedu/v22n68/14132478-rbedu-22-68-0169.pdf>.

ESPÍRITO SANTO. Secretaria da Educação. Currículo Básico Escola Estadual: guia de implementação. Vitória: SEDU, 2009.

GILLY, M. As representações sociais no campo educativo. Educar - UFPR, Curitiba, n. 19, p.231252, 2002. Disponível em: <https://revistas.ufpr.br/educar/article/view/2092/1744>.

GIL-PÉREZ, D.; VILCHES, A. Una alfabetización científica para el siglo XXI - Obstáculos y propuestas de actuación. Investigación En La Scuela, Sevilla, n. 43, p. 27-37, 2001. Disponível em: $<$ https://idus.us.es/xmlui/handle/11441/60304>.

GOLEMBEK, D. A. Aprender e ensinar ciências: do laboratório à sala de aula (e vice-versa). Tradução de Eloisa Cerdan. 2. ed. São Paulo: Sangari do Brasil / Fundação Santillana, 2009.

HEGEL, G. W. F. Fenomenologia do Espírito. Tradução de Paulo Meneses. 5. ed., v. 1, Petrópolis: Vozes, 2000.

JODELET, D. Representações sociais: um domínio em expansão. In: JODELET, D. (Org.). Les représentations sociales. Tradução de Tarso Bonilha Mazzotti e Revisão Técnica de Alda Judith Alves-Mazzotti. Rio de Janeiro: UFRJ - Faculdade de Educação, 1993, p. 1-21.

JOVCHELOVITCH, S. Psicologia social, saber, comunidade e cultura. Psicologia \& Sociedade, n.16, p.20-31, mai./ago. 2004. Disponível em: <http://www.scielo.br/pdf/psoc/v16n2/a04v16n2>.

KRASILCHIK, M.; MARANDINO, M. Ensino de ciência e cidadania. $2^{a}$ ed. São Paulo: Moderna, 2007.

KUHN, T. S. A estrutura das revoluções científicas. 5ª ed. São Paulo: Perspectiva, 1998.

LATOUR, B. Jamais fomos modernos: ensaio de antropologia simétrica. Tradução de Carlos Irineu da Costa. Rio de Janeiro: Ed. 34, 1994.

LATOUR, B.; WOOGAL, S. A vida de laboratório: a produção dos fatos científicos. Tradução de Angela Ramalho Vianna. Rio de Janeiro: Relume Dumará, 1997.

LIMA, N. W.; OSTERMANN, F.; CAVALCANTI, C. J. H. A não-modernidade de Bruno Latour e suas implicações para a Educação em Ciências. Caderno Brasileiro de Ensino de Física, v. 35, n. 2, p. 367-388, ago. 2018. DOI: http://dx.doi.org/10.5007/2175-7941.2018v35n2p367. Disponível em: <https://periodicos.ufsc.br/index.php/fisica/article/view/2175-7941.2018v35n2p367>.

LORENZETTI, L.; DELIZOICOV, D. Alfabetização científica no contexto das séries iniciais. Ensaio Pesquisa em Educação em Ciências, Belo Horizonte, v. 3, n. 1, p. 1-17, jun. 2001. Disponível em: <http://www.scielo.br/pdf/epec/v3n1/1983-2117-epec-3-01-00045.pdf>.

MEC/INEP. Ministério da Educação/ Instituto Nacional de Estudos e Pesquisas Educacionais Anísio Teixeira. Estudo do Professor - Censo Escolar da Educação Básica 2007. Brasília: MEC/Inep, 2007. Disponível em: <http://portal.mec.gov.br/plano-nacional-de-formacao-deprofessores/censo-do-professor>. Acesso em: out. 2017.

MOSCOVICI, S. A psicanálise, sua imagem e seu público. Petrópolis: Vozes, 2012. 
MOSCOVICI, S. Representações sociais: investigações em psicologia social. $5^{a}$ ed. Petrópolis: Vozes, 2007.

ORNELLAS, M. L. S.. Educação, afeto e representação social. In: NASCIMENTO, A. D.; HETKOWSKI, T. M. (org.) Educação e contemporaneidade: pesquisas científicas e tecnológicas. Salvador: EDUFBA, 2009. p. 275-293.

POZO, J. I.; CRESPO, M. A. G. A aprendizagem e o ensino de ciências - do conhecimento cotidiano ao conhecimento científico. $5^{\text {a }}$ ed. Porto Alegre: Artmed, 2009.

SÁ, C. P. A construção do objeto de pesquisa em Representações Sociais. Rio de Janeiro: Ed. UERJ, 1998.

SÁ, C. P. Núcleo central das representações sociais. Petrópolis: Vozes, 1996.

SCHIEL, D.; ORLANDI, A. S. Ensino de ciências por investigação. São Carlos: Universidade de São Paulo, Centro de Divulgação e Cultura - CDCC, 2009.

SHEN, B. S. P. Science Literacy: Public Understanding of Science Is Becoming Vitally Needed in Developing and Industrialized Countries Alike. American Scientist, v. 63, n. 3, p. 265-268, 1975. Disponível em: <www.jstor.org/stable/27845461>.

SPINK, M. J. P. O conceito de representação social na abordagem psicossocial. Cadernos de Saúde Pública, Rio de Janeiro, n.9, p. 300-308, jul./set. 1993. Disponível em: <http://www.scielo.br/pdf/ $\operatorname{csp} / \mathrm{v} 9 \mathrm{n} 3 / 17 . \mathrm{pdf}>$.

VERGÈS, P. L'analyse des représentations sociales par questionnaires. Revue française de sociologie, v. 42, n. 3, p. 537-561, 2001. Disponível em: <https://www.persee.fr/doc/ rfsoc_0035-2969_2001_num_42_3_5373>.

VITTORAZZI, D. L. A ciência, seu ensino e suas representações: implicações na construção do conhecimento científico no ensino fundamental. 2018. 171f. Dissertação (Mestrado em Ciência, Tecnologia e Educação) - Centro Federal de Educação Tecnológica Celso Suckow da Fonseca, Rio de Janeiro.

VOGEL, M. Influências do PIBID na Representação Social de licenciandos em Química sobre ser "professor de Química”. 2016. 201 f. Tese (Doutorado em Ensino de Ciências) - PósGraduação Interunidades em Ensino de Ciências, Universidade de São Paulo, São Paulo.

WACHELKE, J.; WOLTER, R. Critérios de construção e relato da análise prototípica para representações sociais. Psicologia: Teoria e Pesquisa, Brasília, v. 27, n. 4, p. 521-526, out./dez. 2011. Disponível em: <http://www.scielo.br/pdf/ptp/v27n4/17.pdf>.

\section{NOTAS}

1 Trazemos, a este contexto, as reflexões de Hegel (2000) acerca do que ele denomina "realismo ingênuo". Para o autor, o conhecimento do senso comum traz relações com o realismo ingênuo, o qual compreenderia o encargo da aceitação de uma realidade observada como verdade absoluta, sem um pensamento crítico ou reflexivo sobre o objeto em questão, o que permitiria ao indivíduo o reconhecimento de formas de conhecimento incompletas ou insustentáveis. Tal tarefa facultaria a superação ou, até mesmo, a conservação dessas formas de conhecimento. 
2 Bruno Latour (1947-) é professor emérito da Sciences Po Paris e membro de várias academias.Após estudos de campo na África e na Califórnia, ele se especializou na análise de cientistas e engenheiros no trabalho. Além de trabalhar em filosofia, história, sociologia e antropologia da ciência, colaborou em muitos estudos em política científica e gestão de pesquisa. Em uma série de livros, ele vem explorando as consequências dos estudos científicos sobre diferentes tópicos tradicionais das ciências sociais. Escreveu e editou mais de vinte livros e publicou mais de cento e cinquenta artigos. Seu pensamento tem permeado debates nas áreas políticas, científicas e ambientais. Disponível em: $<$ http://www.bruno-latour.fr/biography>. Acesso em: maio de 2019.

3 No estudo das situações reais as práticas sociais podem ser concebidas como "sistemas de ação socialmente estruturados e instituídos em relação com os papéis” (ABRIC, 1994 apud CAMPOS, 2017, p. 44) ou ainda como "conjuntos de condutas finalizadas pelos e para o grupo" (MOLINER, 2001 apud CAMPOS, 2017, p. 44).

4 Tradução livre do Francês Ensemble de Programmes Permettant l'Analyse des Evocations. De acordo com Barcellos et al. (2005), "o Evoc é um programa de informática, elaborado por Pierre Vergès e outros colaboradores, que possui vários subprogramas que permitem a emissão de dados estatísticos para uma posterior análise de evocações pela verificação das frequências das palavras evocadas" (p. 217).

5 Interface de R pour lês Analyses Multidimensionnelles de Textes et de Questionnaires. O IRAMUTEQ é um software livre, desenvolvido por Pierre Ratinaud, ancorado no software $\mathrm{R}$, que permite a realização de análises estatísticas de corpus textuais (CAMARGO; JUSTO, 2013).

6 Destacamos os princípios apontados por Arruda e Flores (2012), ao citarem Julia (2001), de que a cultura escolar se caracteriza como um compêndio de normatizações que especificam os saberes a ensinar, bem como as práticas que permeiam a transmissão destes, os quais podem variar conforme seus contextos temporais.

Submetido: $16 / 07 / 2019$

Aprovado: 10/01/2020

Editor adjunto responsável: Fabio Augusto Rodrigues e Silva

\section{Contato:}

Centro Federal de Educação Tecnológica Celso Suckow da Fonseca (CEFET/RJ)

Programa de Pós-graduação em Ciência, Tecnologia e Educação - PPCTE

Laboratório de Pesquisa em Educação em Ciências e Representações Sociais

Av. Maracanã, 229, Bloco E - $5^{\circ}$ andar - Sala 503-11, Maracanã

CEP. 20271-110 - Rio de Janeiro, RJ - Brasil 